\title{
A DANÇA COMO PRÁTICA DE LAZER: ALGUMAS REFLEXÕES SOBRE HOMENS, GÊNERO E O BALÉ CLÁSSICO
}

\author{
Renata Ferreira dos Santos \\ Universidade Estadual de Campinas, Campinas, São Paulo, Brasil \\ Simone Cassoli Ferraz \\ Universidade de São Paulo, São Paulo, São Paulo, Brasil \\ Marco Antonio Bettine de Almeida \\ Universidade de São Paulo, São Paulo, São Paulo, Brasil \\ Gustavo Luis Gutierrez \\ Universidade Estadual de Campinas, Campinas, São Paulo, Brasil
}

\begin{abstract}
Resumo
Este estudo analisa a questão do gênero relacionada a dança como prática de lazer, especificamente do gênero masculino quanto ao balé clássico, com o propósito de compreender como o homem é visto pela sociedade enquanto bailarino. Para isso foi realizada uma pesquisa bibliográfica, e posteriormente, uma análise sociológica baseada nas obras de Karl Marx, Pierre Bourdieu e Jürgen Habermas. Conclui-se que o gênero é socialmente construído, assim como a dominação masculina que deixa clara a existência de um papel que o homem precisa cumprir para afirmar a sua masculinidade.
\end{abstract}

Palavras-chave: Dança. Lazer. Gênero.

\section{Introdução}

A dança se apresenta como uma forma de manifestação, que representa várias características de uma sociedade. O objetivo deste artigo é analisar a questão do gênero relacionada à dança, especificamente do gênero masculino quanto ao balé clássico, com o propósito de compreender como o homem é reconhecido e considerado enquanto bailarino, e as relações feitas entre esta prática e a sua orientação sexual.

Segundo Rangel (2002), a dança é um fenômeno social. Por estar presente durante toda a história da sociedade, da primitiva à contemporânea, retratando épocas e graus do desenvolvimento social, econômico, cultural, político e religioso. Ela materializou as técnicas, os valores e os significados das civilizações expressando e revivendo os fatos por meio da representação das vivências do homem no mundo e das influências que o mundo lhe apresentava. 
Os povos primitivos utilizavam o movimento corporal como ritual, era sua principal forma de comunicação e comunhão. Os homens dançavam para a colheita, para a fertilização, para a diversão, para fazerem agradecimentos e principalmente como meio de comunicação e entendimento entre os membros da sociedade. Além disso, a dança também era considerada uma ligação entre o homem e seus deuses. Por este motivo, Medina (2011) afirma que a dança fornece elementos ou representações da cultura dos povos, podendo manifestar os hábitos e costumes de uma sociedade.

As pessoas passaram a dançar cada vez mais, principalmente quando ela foi aprimorada, o que possibilitou que toda a movimentação fosse transformada em diversão e entretenimento. A dança pode ser praticada como forma de expressão artística, expressão humana, expressão de sentimentos e expressão da sociedade, como forma de aquisição de conhecimentos, de práticas de lazer, de prazer, como libertação da imaginação, desenvolvimento da criatividade e da comunicação, e como veículo de socialização (BARRETO, 2004).

Caminada (1999) afirma que a necessidade de liberação de sua vida interior foi o que motivou o homem pré-histórico a dançar, pois os sentimentos vivenciados durante esta prática estão relacionados à necessidade de amparo, de abrigo, de alimento, de defesa, de conquista, de procriação, de saúde e de comunicação.

Segundo Viana (2005): "mais do que uma maneira de exprimir-se por meio do movimento, a dança é um modo de existir", pois, são infinitas as possibilidades de movimento do corpo humano e esses movimentos são impulsionados por motivações interiores que brotam exteriormente através dos gestos.

A princípio, a dança não carregava preocupações com a qualidade técnica, alto desempenho ou máximo rendimento do corpo, nem pela busca da perfeição como existe atualmente. Sua presença era muito mais próxima do cotidiano das pessoas, ela apresentava-se a qualquer ocasião, e não em um momento específico. No processo histórico, a humanidade começou a construir grupos pela diferenciação, o que possibilitou que a dança representasse estes grupos específicos, logicamente a dança começa a representar um povo (BOURCIER, 1987).

Foi na corte francesa que surgiu o primeiro bailarino do qual se tem relato: Luís XIV. Juntamente com ele, houve o surgimento das escolas de dança, fazendo com que esta prática ganhasse forma de profissionalização e entretenimento, perdendo assim as suas primeiras características, dançar para os deuses, para colheita, para o acasalamento, para os mortos. Neste período foram estabelecidas regras e técnicas, e o balé clássico surgiu trazendo consigo a exigência de horas de ensaios, perfeição de movimentos e gestos.

Embora haja relatos que um homem foi o primeiro bailarino, o que carece de comprovação histórica, já que as mulheres sempre foram alijadas do processo histórico, nos dias atuais, ainda existe certo preconceito quanto aos homens que dançam balé clássico.

A palavra gênero tem diversos significados, neste momento vamos apresentar uma pequena discussão do gênero, e posteriormente relacionar com a dança. Primeiramente gênero é uma categoria sociológica, uma categoria que indica por meio de desinências uma divisão dos nomes baseada em critérios, tais como sexo e associações psicológicas. Há gêneros masculino, feminino e neutro. O uso gramatical implica em regras formais decorrentes da designação de masculino ou feminino, que é cheia de possibilidades inexploradas, pois em vários idiomas indo-europeus existe uma terceira categoria - o sexo indefinido ou neutro. Observando a gramática, gênero é 
compreendido como um meio de classificar fenômenos, um sistema de distinções socialmente acordado, mais do que uma descrição objetiva de traços inerentes (SCOTT, 1989).

Segundo Joan Scott (1989), o "gênero" aparentemente surgiu primeiro entre as feministas americanas que insistiam no caráter fundamentalmente social das distinções baseadas no sexo. Gênero indicava uma rejeição ao determinismo biológico implícito no uso de termos como "sexo" ou "diferença sexual". As mulheres centravam-se sobre elas de forma extremamente estreita e isolada, utilizando o termo "gênero" para introduzir uma noção relacional no nosso vocabulário analítico. De acordo com essa opinião, tanto as mulheres quantos os homens eram definidos em termos recíprocos e nenhuma compreensão de qualquer um poderia existir através de um estudo inteiramente separado.

Deve-se haver um interesse maior pela história tanto dos homens quanto das mulheres, objetivando o entendimento da importância dos sexos dos grupos de gênero no passado histórico, na busca de descobrir a amplitude dos papéis sexuais e do simbolismo sexual nas várias sociedades e épocas, achar quais eram os seus sentidos e como funcionavam para manterem a ordem social e para mudá-la (DAVIS, 1975).

A forma como esta história iria incluir e apresentar a experiência das mulheres dependeria da maneira como o gênero poderia ser desenvolvido como uma categoria de análise. Os interesses pelas categorias de classe e de gênero marcam primeiramente o compromisso do pesquisador com a história, que também incluía a fala dos oprimidos, com uma análise do sentido e da natureza de sua opressão: assinalava também que esses pesquisadores levavam em consideração o fato de que as desigualdades de poder estão organizadas segundo estes três eixos (SCOTT, 1989). Os três eixos são raça, classe e gênero, neste texto não discutiremos a questão raça.

A categoria de "classe" está baseada numa visão marxista da determinação econômica e da mudança histórica, a gênero não veicula tal associação. Não há unanimidade entre os que utilizam os conceitos de classe. Max Weber, por exemplo, amplia o debate, na medida em que se separam na sua teoria as dimensões econômicas, políticas e sociais da distribuição do poder na sociedade. Contudo, quando se menciona "classe", trabalha-se com ou contra uma série de definições que no caso do marxismo implica uma ideia de causalidade econômica e uma visão do caminho pelo qual a história avançou dialeticamente. Para uma visão de Marx, dentre as várias possíveis, a alienação do homem no trabalho, isto é na sua infraestrutura, e sua condição de classe impede a superação de outras esferas da vida, superestrutura. Só é possível superar condições de gênero, se o alienado no trabalho superar esta condição. Em outras discussões como Bourdieu (1999, p?), a questão de classe é substituída, pela questão do poder, neste caso não há uma hierarquia, mas sim, várias frentes para superarmos os antagonismos de gênero, conforme iremos discutir no próximo item.

Para Benhabib e Cornell (1987), o conceito de indivíduo é prejudicado pela desigualdade, assimetria e dominação que permeia a identidade privada desse sujeito dotado de gênero. $\mathrm{O}$ enfoque liberal do eu tem a perda da compreensão do eu dotado de gênero.

Mas a identificação de gênero é extremamente instável. As identidades subjetivas são processos de diferenciação e de distinção, que exigem a supressão das ambiguidades e dos elementos opostos com a finalidade de assegurar uma coerência e uma compreensão comuns. $\mathrm{O}$ princípio de masculinidade tem como base a repressão necessária dos aspectos femininos - do potencial bissexual do sujeito - e introduz o conflito na oposição entre o masculino e o feminino. Desejos reprimidos estão presentes no inconsciente e constituem uma ameaça permanente para a 
estabilidade da identificação de gênero, de forma a negar sua unidade e subvertendo a necessidade de segurança (SCOTT, 1989).

\section{O Ser Social (Karl Marx)}

O trabalho, na visão marxista, é a única forma de obtenção da riqueza, não apenas sob o aspecto econômico, mas também sob o aspecto cultural, e é por meio do trabalho que as pessoas geram a riqueza e os instrumentos que serão utilizados e apropriados para as gerações futuras.

A riqueza não se resume a uma simples acumulação de bens materiais, mas sim, a apropriação dos bens produzidos no decorrer da evolução do gênero humano (MARX, 1991).

Há uma aproximação tanto do operário quanto do burguês, pois ambos não refletem a essência do homem enquanto homem, mas uma expressão alienada dessa essência: o operário tornou-se tão preocupado com o que necessita para sobreviver que não é capaz de admirar qualquer forma de expressão artística, e o burguês, está tão preso ao valor comercial do produto que sua beleza já não tem importância, pois ele não aprecia o produto artístico enquanto arte, ou seja, tanto o operário quanto o burguês, não conseguem se formar enquanto verdadeiros representantes do homem moderno em sua liberdade, ou melhor, enquanto Ser Social (MARX, 1991).

O homem chega a ser incapaz de se reconhecer na atividade que realiza, porquê, está alienado da sua função social no trabalho ${ }^{59}$. O trabalho auxilia na tomada de consciência, com vistas à formação do ser social enquanto partícipe do gênero humano, para possibilitar que este venha a desenvolver todas as suas particularidades em meio aos complexos sociais que constituem a totalidade.

Na contra mão da concepção de trabalho que é proposta pela sociabilidade do capital, com enfoque na reprodução do metabolismo do capital em favor da formação do ser social na sua totalidade, o trabalho como essência humana, sendo fragmentado confere uma relação objetividade/subjetividade de certa forma alienada, afeita ao pragmatismo e em oposição à filosofia da práxis.

Os homens são os protagonistas da sua própria história, entretanto, "não a fazem segundo sua livre vontade, em circunstâncias escolhidas por eles próprios, mas nas circunstâncias encontradas, dadas e transmitidas pelo passado", pois cada sociabilidade comporta inúmeras possibilidades e limitações histórico-sociais particulares. Portanto, o homem moderno na dança não irá refletir, por uma visão restrita aqui desenvolvida, a sua arte, pois ele está inserido no fetichismo da mercadoria e vende sua arte, para outros homens, que tem a sua vida alienada, e presa aos valores do capital, da mercadoria, a arte, hoje, segundo leitura de Walter Benjamin, perdeu sua áurea, logo está presa aos determinantes sociais do capital. Para aprofundar a questão do gênero na dança, vamos nos utilizar de Bourdieu que trabalha com estas questões.

${ }^{59}$ Exemplo da alienação está no filme Tempos Modernos, onde o ator principal Charles Chaplin atuava um operário em meio a rodas dentadas, e não tinha noção do que se produzia, pois a sua parcela na produção era ínfima e apartada do produto em sua totalidade. 


\section{A Dominação Masculina (Pierre Bourdieu)}

Segundo Bourdieu (1999), a divisão entre as relações sociais de dominação entre os gêneros separa-se em duas classes de 'habitus' diferentes, que levam à classificação das coisas do mundo e das práticas segundo a distinção e oposição entre o masculino e o feminino. O habitus é um sistema de disposições, tendências incorporadas pelo indivíduo decorrentes da especificidade do processo de socialização por ele vivido. As disposições são estruturadas e estruturantes sendo determinadas pelas condições sociais mais estruturais que se apresentam no processo de socialização dos sujeitos, ao mesmo tempo em que concorrem para a determinação das práticas destes sujeitos.

A divisão socialmente construída entre os sexos acaba sendo legitimada por ser vista como uma questão natural e evidente.

O mundo social constrói o corpo como realidade sexuada e como depositário de princípios de visão e de divisão sexualizantes. Esta construção abrange principalmente o corpo em sua estrutura biológica, pois é esta formação estrutural que diferencia os sexos. A diferença biológica entre o corpo masculino e o corpo feminino, e principalmente a diferença anatômica entre os órgãos sexuais, pode justificar esta diferença socialmente construída entre os gêneros.

Um sujeito com o objetivo de provar que de fato é um verdadeiro homem necessita demonstrar sua virilidade como um ponto de honra, apresentando seu nível de potência sexual. Mesmo sendo compostos da mesma fisiologia, o homem e a mulher são vistos como se fossem duas variáveis, sendo uma superior e a outra inferior. Esta diferenciação é bem dividida em uma série de oposições mítico-rituais: alto/baixo, em cima/em baixo, seco/úmido, quente/frio, ativo/passivo, móvel/imóvel, que sustentam a ideia de que o homem é superior, pois fica por cima. Algumas civilizações chegam inclusive a condenar a posição amorosa na qual a mulher se põe por sobre o homem.

Todas estas oposições relacionam o ato sexual a uma relação de dominação, que se dá no sentido de submeter alguém a seu poder, à tomada de posse.

$\mathrm{O}$ ato sexual se dá em uma relação de dominação em que os homens dominam, apropriamse, possuem as mulheres. A relação sexual apresenta-se como uma relação social de dominação, pois ela se origina da divisão entre o masculino ativo e o feminino passivo, tendo o masculino o desejo de posse como dominação erotizada, e o feminino o desejo da dominação masculina, como subordinação erotizada.

A esta dominação podemos relacionar a homossexualidade, neste caso, a reciprocidade é possível nas relações sexuais, mas os papéis ativos ou passivos são indissociáveis das relações sociais, pois o ativo continua sendo o dominante e o passivo o dominado, porém no caso, o passivo além de ser dominado é feminizado pelo outro. Sendo a sexualidade referente ao poder, a pior humilhação para um homem é ser transformado em mulher.

O corpo é diferenciado socialmente a partir do gênero oposto, o masculino não feminino e o feminino não masculino. Esta definição social quanto à distinção sexual acaba impondo quais práticas convém para cada sexo, proibindo ou desencorajando as condutas consideradas impróprias, como o homossexualismo, ou práticas que podem ser associadas a ele.

A dominação masculina não é invariável ou eterna, mas sim, um produto de um trabalho incessante de reprodução de agentes e instituições, como a família, a igreja, a escola e o estado.

Por causa da socialização as mulheres são diminuídas e negadas, porém os homens também são prisioneiros e vítimas da representação dominante, tendo que se submeter a exercer a 
dominação, como capacidade reprodutiva, sexual e social. A preocupação em demonstrar a virilidade a todo o momento acaba por ser uma carga, uma vez que os homens têm quase que por obrigação a responsabilidade de envolver-se em atividades que demonstrem sua masculinidade, como por exemplo, os esportes de luta, fugindo de qualquer imagem que lhes façam apresentar alguma fraqueza ou vulnerabilidade, ou seja, que possa se opor à sua virilidade.

As atitudes tomadas são construídas sobre o medo de ser discriminado ou ser submetido a categorias femininas, podendo ser chamados de fracos, delicados e mulherzinhas, e pelo receio de serem excluídos do mundo dos homens sem fraquezas. A virilidade é construída diante de outros homens, para outros homens e contra a feminilidade, como se existisse uma espécie de medo do feminino, o que é subjetivo.

A masculinização do corpo masculino e a feminilização do corpo feminino são tarefas intermináveis que levam tempo e necessitam de muito esforço. A família auxilia para esta dominação com a exigência da inserção em um trabalho, que também possui uma divisão sexual, existindo trabalhos para homens e trabalhos para mulheres. A igreja é marcada pelo antifeminismo considerando a matéria de trajes, e uma visão pessimista relacionando a inferioridade à mulher. A escola é responsável por ensinar as maneiras de ser e as maneiras de ver e de se ver, enfim, os modos de se pensar.

O homossexualismo não passa de uma construção social, assim como a heterossexualidade que é construída como padrão universal de toda prática sexual "normal".

Não ignorando a importância do Ser Social em Marx, mas o conceito aqui proposto de Bourdieu busca refletir sobre a situação atual e a possibilidade de combater a heteronormatividade com os elementos sociais que a constituíram, pois se o homem foi capaz de construir socialmente a diferenciação entre os gêneros cabe a sociedade repensar e reconstruir este modelo de Poder. Enquanto na visão apresentada no Ser Social, essa transformação e a liberdade de gênero e de escolha, seria possível com a emancipação do homem no mundo do trabalho, através da transformação da infraestrutura.

Aqui propomos, no próximo item, com Habermas e sua Teoria da Ação Comunicativa (1987), uma ideia de síntese que não negará a importância do trabalho nas relações sociais (agir estratégico), mas também consegue entender a superação das relações do poder ao valorizar a comunicação para transformação (agir comunicativo).

\section{A Emancipação do Homem na Vida Social (Jürgen Habermas)}

O trabalho, pela essência de dominar a natureza para colocá-la a serviço do homem, possui uma racionalidade do mesmo tipo da racionalidade da ciência e da técnica, ou seja, uma racionalidade pautada na organização e na escolha adequada de meios para atingir determinados fins.

A ciência e a técnica ampliam as possibilidades humanas, de forma a libertar o homem do jugo das necessidades materiais, sendo o desenvolvimento da espécie humana resultado de um processo histórico de desenvolvimento tecnológico, institucional e cultural, processos esses, que são interdependentes.

Existem dois âmbitos do agir humano contido no conceito de Marx de "atividade humana sensível", que são interdependentes: o trabalho e a interação social. O "trabalho" ou "ação racional teleológica" é o processo pelo qual o homem emancipa-se progressivamente da natureza. Por sua 
vez, a "interação", entende a esfera da sociedade em que normas sociais se constituem a partir da convivência entre sujeitos, capazes de comunicação e ação.

Desta forma o homem não reage simplesmente a estímulos do meio, mas também atribui um sentido às suas ações e, por meio da linguagem, é capaz de comunicar percepções e desejos, intenções, expectativas e pensamentos, possibilitando o vislumbre da possibilidade de que, através do diálogo, o homem possa retomar o seu papel de sujeito.

O interesse primordial de Habermas foi construir uma teoria crítica da sociedade para possibilitar a emancipação do homem na vida social, por meio do desenvolvimento de suas potencialidades de auto-reflexão. Ele utiliza como base a herança kantiana para discutir uma teoria social que resgata o sentido esquecido da racionalidade.

Existem diferentes tipos de ação de acordo com a relação que o homem estabelece com o mundo. $\mathrm{O}$ agir racional com respeito a fins manifesta-se de duas formas: o agir instrumental e o agir estratégico, sendo que o primeiro tende a organizar os meios adequados ou inadequados segundo os critérios de um controle eficaz da realidade, o segundo depende de uma avaliação correta das possíveis alternativas do comportamento, que resulta de forma exclusiva de uma dedução feita com o auxílio de valores e de máximas.

Habermas diferencia a orientação para o entendimento mútuo da orientação para o sucesso, ao abordar a estrutura do agir orientado para o entendimento mútuo, de forma a explicar que os atores são orientados exclusivamente para o sucesso (para as consequências de seu agir) tentando alcançar os objetivos de sua ação influindo externamente por meio de armas ou bens, ameaças ou seduções, sobre a definição da situação ou sobre as decisões ou motivos de seu adversário.

A ideia da ação comunicativa, que visa à emancipação social complementa o pensamento de que a criatividade será mais desenvolvida quanto mais livre for uma sociedade. Apenas os indivíduos suficientemente capazes de estabelecer relações verdadeiras e livres de qualquer tipo de dominação poderão adquirir a liberdade de pensamento e consequentemente, de criação.

Critica-se a racionalidade instrumental e defende-se a racionalidade comunicativa, que é a única forma de levar o homem ao entendimento, pois o livre fluxo das ideias passa pela liberdade de pensamento, e também pelo rompimento com a dominação social que permeia as relações sociais.

Sendo assim, tanto a criatividade quanto a racionalidade são componentes intrínsecos do ser humano, e infelizmente seus princípios têm sido deturpados para obedecerem e sustentarem a lógica vigente de mercado.

Os valores que buscamos aqui é que o Ser Social em Marx se realize, independentemente de qual modelo econômico estão inseridos, e que a superação do poder construído culturalmente do macho dominante seja reconfigurado buscando nas ações comunicativas, os consensos para materializar as transformações sociais. Neste caso, ao inserir o homem na dança e a valorização deste espaço de expressão, estamos na contramão nos valores dominantes e próximo da transformação da ideia de gênero.

\section{A inserção do homem na dança}

Do século XV ao século XVIII, o balé clássico operou uma eficiente pedagogia da masculinidade. Juntamente com outras práticas corporais como a esgrima, ele era considerado um meio eficaz para se formar "homens", ou seja, para generificar corpos masculinos. Ele estava associado a um modelo de masculinidade hegemônico, denominado de o "patriarca gentil": o nobre 
europeu, aristocrático, refinado, elegante, que tinha valor e que provava a sua masculinidade por meio da execução de gestos corporais suaves, delicados e sensuais. Nesta época, a dança era considerada pela sociedade uma atividade masculina natural, e em contrapartida, uma prática imprópria para as mulheres (ANDREOLI, 2011).

Esta situação é invertida na metade do século XVIII e início do século XIX, uma vez que os ideais modernos de masculinidade são construídos como forma de resposta a uma crescente necessidade de organização das relações sociais, oriundas de um novo processo civilizador (ANDREOLI, 2011).

Com a Revolução Industrial e aparecimento das sociedades burguesas, houve o surgimento de uma nova representação de masculinidade associada à produção, à eficiência, à racionalidade e à produtividade, e a distinção entre a homossexualidade e a heterossexualidade foi criada, fazendo com que novas normas fossem estabelecidas para o gênero e a sexualidade masculinas. Tida como um desvio da natureza, a homossexualidade passou a ser considerada uma sexualidade degradada, e também associada à falta de masculinidade. O balé clássico então, com a sua estética originária da nobreza do século XVIII, (o modelo de masculinidade anterior), começou a ser negada por essa nova representação.

Foi com o propósito de sustentar esse novo modelo hegemônico de masculinidade que surgiram representações que construíram a noção de que homens que dançam não são totalmente homens, e no momento em que houve essa desvalorização da dança como atividade masculina, o balé clássico passou a ser associado ao feminino (ANDREOLI, 2011).

Stinson (1998) afirma que os professores de dança geralmente reclamam que principalmente depois da primeira infância, poucos são os meninos que se matriculam voluntariamente em suas turmas. Sua pesquisa relata que a maior preocupação revelada pelos meninos de 10 a 15 anos, alunos de dança em ambientes escolares, é a de que a dança fosse uma "aula para meninas", enquanto que a preocupação dos meninos mais velhos era a de que as pessoas pudessem pensar que eles eram homossexuais por frequentarem aulas de dança ${ }^{60}$.

No campo profissional, quase todos os coreógrafos desejam ter mais dançarinos em suas obras, e as intérpretes mulheres, comumente reclamam que dançarinos menos treinados possuem mais oportunidades de emprego do que as dançarinas mais qualificadas (STINSON, 1998).

$\mathrm{Na}$ teoria social clássica, presumia-se que as diferenças entre os lugares ocupados por homens e mulheres na divisão social do trabalho fosse "natural", com base na dessemelhança entre os seus papéis na reprodução biológica. Alguns pressupostos semelhantes encontram-se no estruturalismo funcionalista de Talcott Parsons, que desenvolveu uma teoria dos papéis sexuais enraizados na diferenciação entre ação expressiva e instrumental na família conjugal (SCOTT, 2010).

De acordo com Parsons, as mulheres adotavam papéis expressivos, e os homens, papéis instrumentais. Os papéis sociais são associados a determinadas posições na divisão social do trabalho, e fornecem roteiros da feminilidade e da masculinidade que são aprendidos por meio do

${ }^{60}$ Billy Elliot, filme de 2000, diretor Stephen Daldry. É a história de um garoto de 11 anos, Billy Elliot, que vive numa pequena cidade inglesa, onde o principal meio de sustento são as minas da cidade. Billy começa a praticar Balé de maneira escondida, nesta trama a questão do trabalho, do poder e da comunicação, tal qual a discussão neste texto é trabalhado, podendo servir como material didático nas aulas de Educação Física. 
processo de socialização. Estes roteiros são diferenciados para meninas e meninos de acordo com o gênero (SCOTT, 2010).

A socialização é condicionada de acordo com o gênero e corresponde ao sexo biológico, enquanto que a cultura se desenvolve sobre um alicerce fornecido pela natureza. Este desenvolvimento não é predeterminado, e por isso, a socialização pode ser "falha", o que pode levar à aquisição de papéis sexuais "inadequados". Portanto, essa "falha" pode ser usada para explicar a homossexualidade ou outros "desvios" em relação aos papéis sexuais normativos (SCOTT, 2010).

De acordo com alguns teóricos, a busca da identidade de gênero é diferente para meninos e meninas devido o fato de a mulher ser geralmente a primeira pessoa a cuidar de uma criança. Desta maneira, a menina estabelece sua feminilidade pela identificação e pela ligação com a mulher que dela cuida, e diante disso, passa a enxergar o mundo como um local feito de relações, como uma "teia de relações", enquanto que o menino sob os cuidados de uma mulher precisa realizar uma separação e tornar-se "outro", com o objetivo de estabelecer sua masculinidade; o que o leva a ver o mundo como um lugar constituído de partes separadas em competição umas com as outras - "cada um por si". Estas maneiras diferentes de ver o mundo não se aplicam a todos os homens nem a todas as mulheres, porém, afetam a forma como a maioria dos homens e das mulheres se comunica, tomam decisões morais, e aprendem a pensar criticamente, pelo menos na cultura ocidental (STINSON, 1998).

Assim, o menino precisa estabelecer sua própria individualidade, e definir-se como "outro" em relação à mulher, para conseguir definir-se como homem. $\mathrm{O}$ menino pode vir a interpretar a masculinidade apenas como o oposto do que considera como feminino, especialmente se privado do contato masculino, e sendo assim, a tentativa da mãe que sozinha cria um filho, ensinando-o a ser sensível e carinhoso, pode frequentemente, ter o efeito oposto (STINSON, 1998).

Mesmo que a quantidade de modelos masculinos na dança aumentasse, isso não significaria necessariamente que os meninos se sentiriam mais à vontade de ver a dança do mesmo ponto de vista das meninas. O "problema dos meninos e dança" está relacionado a uma homofobia desenfreada e ao status inferior da mulher na sociedade.

Stinson relata que a maioria das pessoas que estão envolvidos no ensino da dança, mantevese calada a despeito do grande número de dançarinos gays vitimados pela AIDS, apenas protestando ocasionalmente dizendo que nem todos os homens na dança são gays. Esta situação demonstra que parece que há uma preocupação com o fato de que tais ideias sobre homens e dança mantenham os homens que poderiam dar status à dança afastados desta profissão. Stinson afirma que o problema não é a homossexualidade, mas sim as atitudes que muitas pessoas adotam a respeito do assunto.

\section{Considerações finais}

A dança está ligada a uma série de condições sociais de estruturas dominantes. A compreensão de como os segmentos sociais percebem os corpos que dançam são de extrema importância, além da compreensão da visão que a sociedade determina sobre estes.

O preconceito e discriminação existiriam por causa da construção social que impõe a ideia de gênero que determina quais são os comportamentos que se encaixam dentro de um determinado padrão, distinguindo certas atividades como masculinas ou femininas, sendo estas utilizadas como representações sociais e culturais dentro da construção social. Homens que se afastam deste padrão são expostos a discriminações e subordinações. 
Essa composição nos faz sugerir a possibilidade dos condicionamentos sociais relacionados ao gênero, terem favorecido as mulheres na construção de um habitus, de modo geral, associando a dança à feminilidade (BOURDIEU, 1996).

Considerada uma prática relativamente feminina, um homem não poderia fazer parte dela, pois estaria fugindo do padrão de masculinidade. Os movimentos leves do balé clássico, a flexibilidade e a demonstração de sentimentos relacionar-se-iam à fraqueza e à vulnerabilidade, características apontadas como femininas, estereotipando bailarinos como delicados e trazendo decorrentes dúvidas quanto a sua heterossexualidade, perante a afirmativa de que um homem deve demonstrar a sua virilidade e não se diminuir, tomando atitudes inferiores características de mulheres. Se um homem opta por realizá-las, logo ele se coloca em posição de dominado, e se faz parte da classe de dominados assim como as mulheres, não pode ser chamado de masculino, de viril, sendo consequentemente estereotipado como homossexual, numa visão bourdieana.

O distanciamento do convívio de homens com a dança é um condicionamento estabelecido pelas estruturas sociais. A própria sociedade reforça que determinados tipos de dança são direcionados ao gênero feminino, porém o estilo da dança também interfere nesta construção: Bailarinos são discriminados e estereotipados de homossexuais ou afeminados, enquanto que dançarinos de hip hop, por exemplo, possuem uma maior aceitação social, uma vez que a sua prática não é relacionada à sua orientação sexual, por ser composta por movimentos considerados mais fortes, mais "masculinos".

O gênero é socialmente construído, assim como a dominação masculina que deixa clara a existência de um papel que o homem precisa cumprir para afirmar a sua masculinidade, o que vai além da estrutura anatômica, contando com atitudes que precisam ser demonstradas a todo o momento, a fim de afirmar sua superioridade sobre as mulheres continuamente. $\mathrm{O}$ balé clássico associa-se a movimentos leves, corpos flexíveis e a demonstração de sentimentos, características relacionadas principalmente às mulheres. Por mais que esta prática seja associada à feminilidade, ela teve sua origem com Luís XIV, um homem da corte francesa, o que mostra que esta prática nunca teve seu foco voltado exclusivamente para as mulheres.

Podemos observar que tanto as mulheres quanto os homens são vítimas desta dominação que lhes é imposta, porém a pressão sobre os homens que dançam, muitas vezes os leva a deixar de praticar o balé clássico, devido a cobranças sociais vindas principalmente da família, dos amigos e da igreja, fazendo com que muitos acabem desistindo de uma futura carreira ou simplesmente de um hobby a ser praticado em seu tempo de lazer.

O balé clássico não possui relação direta com a orientação sexual dos bailarinos, pois esta não pode ser definida como sendo uma consequência decorrente da execução de determinados movimentos corporais, de um corpo flexível ou de expressões emocionais.

As práticas corporais possibilitam a construção da imagem, o homem é discriminado no balé clássico assim como a mulher é discriminada no futebol, porém esta construção da imagem não apresenta todo o contexto vivenciado pelo indivíduo. Mesmo nas escolas de dança, os bailarinos são comumente cobrados por seus professores a mostrarem uma imagem masculina enquanto dançam, independente de sua orientação sexual. Sendo assim, esta diferenciação entre o masculino e o feminino é valorizada, mesmo no mundo da dança. 


\title{
DANCE PACTICE AS LEISURE: SOME REFLECTIONS ON MEN, GENDER, AND CLASSICAL BALLET
}

\begin{abstract}
This study examines gender issues related to dance as leisure practice, specifically regarding males in classical ballet, with the purpose of understanding how society views man as a dancer. To this end, we have performed a bibliographic research and subsequently, a sociological analysis based on the works of Karl Marx, Pierre Bourdieu, and Jürgen Habermas. We have concluded that gender is socially constructed, as well as the male domination, which makes clear the existing role that men is supposed to fulfill in order to assert their masculinity.
\end{abstract}

Keywords: Dance. Leisure. Gender.

\section{LA PRÁCTICA DE LA DANZA COMO EL OCIO: ALGUNAS REFLEXIONES SOBRE LOS HOMBRES, DE GÉNERO Y EL BALLET CLÁSICO}

\section{Resumen}

Este estudio examina las cuestiones de género relacionadas con la danza como práctica de ocio, los machos específicamente como el ballet clásico, con el fin de comprender cómo el hombre es vista por la sociedad como un bailarín. Para ello se realizó una búsqueda en la literatura, y, posteriormente, una basada en la obra de Karl Marx, Pierre Bourdieu, Jürgen Habermas y el análisis sociológico. Llegamos a la conclusión de que el género es una construcción social, como la dominación masculina que pone de manifiesto la existencia de un papel que el hombre debe cumplir para afirmar su masculinidad.

Palabras clave: Danza. Ocio. Género.

\section{Referências}

ANDREOLI, G. S. Representações de masculinidade na dança contemporânea. Revista Movimento, 2011, v. 17, n. 01, p. 159-175.

BARRETO, D. Dança ...: ensino, sentidos e possibilidades na escola. Campinas, SP: Autores Associados, 2004.

BENHABIB, S. CORNELl. Feminismo como Crítica da Modernidade. Rio de Janeiro: Paz e Terra, 1987.

BOURCIER, P. História da dança no ocidente. São Paulo: Martins Fontes, 1987.

BOURDIEU, P. (1999). A Dominação Masculina. Rio de Janeiro: Bertrand Brasil.

CAMINADA, E. História da dança: evolução cultural. Rio de Janeiro: Sprint, 1999.

DAVIS, N. Z. “Women'es History in Transition: The European Case”, Feminist Studies, 3 (Winter 1975-76), p. 90. 
HABERMAS, J. Consciência moral e agir comunicativo. Rio de Janeiro: Tempo Brasileiro, 1989.

HABERMAS, J. Técnica e ciência como ideologia. Lisboa: Edições 70, 1987.

HABERMAS, J. Teoria de la acción comunicativa, I: Racionalidad de la acción y racionalización social. Madri: Grupo Santillana de Ediciones S.A, 1999.

LANDINI, T. S. Jogos Habituais - Sobre a noção de habitus em Pierre Bourdieu e Norbert Elias. X Simpósio Internacional Processo Civilizador, Universidade Estadual de Campinas, 2007.

LOURO, G. L. Gênero, sexualidade e educação: Uma perspectiva pós estruturalista. Rio de Janeiro: Vozes, 1997.

MARX, K. Manuscritos econômico-filosóficos, São Paulo: Nova Cultura, 1991, p.165-188.

MARX, K. O 18 Brumário de Luís Bonaparte. A Revolução Antes da Revolução. São Paulo: Expressão Popular, Coleção Assim Lutam os Povos, 2008.

MEDINA, J. et al. As Representações da Dança: uma Análise Sociológica. Artigos Originais. Porto Alegre: Movimento: 2008, v. 14, n. 02, p. 99-113.

Oxford English Dictionary, Ed. 1961, vol. 4.

PEREIRA, M. E. et al (org.). Gênero e diversidade na escola: Formação de professores em gênero, sexualidade, orientação sexual e relações étnico-raciais. Rio de Janeiro: CEPESC. 2007.1 CD ROM.

RANGEL, N. B. C. Dança, educação, educação física; propostas de ensino da dança e o universo da educação física. São Paulo: Fontoura, 2002.

SCOTT, J. - Gender: a useful category of historical analyses. Gender and the politics of history. New York: Columbia University Press, 1989.

SCOTT, J. (org); tradução Carlos Alberto Medeiros; consultoria técnica Luiz Fernando Dias Duarte. Rio de Janeiro: Zahar, 2010.

STINSON, S. Reflexões sobre a dança e os meninos. Revista Pro - Proposições, vol. 9, n. 2, 1998.

VIANNA, K. A dança; em colaboração com Marco Antonio de Carvalho. 3 ed. São Paulo: Summus, 2005. 
Recebido em: 12/09/2014

Revisado em: 19/03/2015

Aprovado em: 30/03/2015

Endereço para correspondência:

Gustavo Luis Gutierrez

gutierrez@fef.unicamp.br

Universidade Estadual de Campinas, Faculdade de Educação Física.

Caixa Postal 6134

Cidade Universitária Zeferino

13083-970 - Campinas, SP - Brasil 